\title{
Investigation of the High Energy Single Pulses Affect on Micro Arc Oxidation Process on Aluminium
}

\author{
Mustafa Safa Yilmaz ${ }^{1 *}$, Orhan Sahin² \\ ${ }^{1}$ Fatih Sultan Mehmet Vakif University, Aluminium Test and Training Center, Halic Campus \\ Istanbul, Turkey \\ msyilmaz@fsm.edu.tr *corresponding author \\ ${ }^{2}$ Gebze Technical University, Material Sceince and Engineering Departmant, \\ Kocaeli, Turkey \\ osahin@gtu.edu.tr
}

\begin{abstract}
Micro Arc Oxidation (MAO) was applied by using high anodic (500 volt) and high cathodic (500 volt) voltages with increasingly pulse duration couples (anodic and cathodic single pulses). While the increasing pulse duration, the single pulse energy was increased also. Due to the investigation of the single pulse affect, all other parameters were kept constant, such as duty cycle (8\%), electrolyte temperature $\left(25 \pm 5^{\circ} \mathrm{C}\right)$, electrolyte composition $\left(\mathrm{KOH}, \mathrm{Na}_{2} \mathrm{SiO}_{3} .5 \mathrm{H}_{2} \mathrm{O}\right)$, process time $(20$ minutes), anodic voltage, cathodic voltage and substrate. Five different anodic and cathodic pulse durations were applied. Scanning electron microscope (SEM), indenter, profilometer, eddy current, X-ray diffractometer were employed to investigate the microstructure, hardness, surface roughness, coating thickness and phase distribution of the coatings. The pore volume and distribution of the coating layers were analysed. Varying of pulse duration occurred significant differences among coating specifications. Coating layers with thickness between 50-90 $\mu \mathrm{m}$ and surface roughness between 3.1-5.2 $\mu \mathrm{m}$ were obtained. The hardness of coating layers was between 800-2000 Vickers. Coatings consist of two layers, inner dense layer and outer porous layer, which was a mixture of $\gamma-\mathrm{Al}_{2} \mathrm{O}_{3}$ and $\alpha-\mathrm{Al}_{2} \mathrm{O}_{3}$.
\end{abstract}

Keywords: Aluminium, Coating, Micro Arc Oxidation, Surface Characterization.

\section{Introduction}

Aluminium and its alloys used in several industries such as automotive, aerospace and transportation. This interest in comes from its high strength to weight ratio, convenient corrosion resistance and lightweight. On the other hand, their disadvantages are low wear resistance, low hardness and hard to lubricate, hence they have limited usage area [1]. Some surface treatments have applied on aluminium alloys for improving their mechanical and tribological properties [2-5].One of the alternative system is Micro-Arc Oxidation which performs thick and hard alumina coatings at bulk material and acquired wear resistance, thermal resistance and corrosion resistance surfaces [6-9]. The properties of MAO coatings are identified by some parameters, such as electrolyte composition, applied power modes, applied power modes, additives, processing temperature, substrate, processing time, etc. Currently it has investigated that bipolar pulsed current mode formed thicker and more uniform coatings according to DC, AC or pulsed unipolar current mode.

Results showed that the electrical parameters, such as current mode, applied voltage, applied current, etc., made differences on MAO coatings. However, our knowledge of the effect of pulse duration on coating properties was not yet investigated. Thus, the aim of this study was examined the effect of anodic-cathodic pulse couple duration on structure and morphology of MAO coatings on aluminium alloy.

\section{Experimental Details}

MAO system exists with two high frequency converters (HFC), which are separately for positive and negative polarity with power of $12,5 \mathrm{~kW}$. These HFC's are working the range of voltage in between $0-800 \mathrm{~V}$. The schematic picture of the MAO device is given in Fig.1 [10]. Bipolar pulse current mode was used in this research. The Tektronix-TDS 2024C digital storage oscilloscope was used for the controlling of voltage, pulse durations and amplitude. The cooling system, which has refrigerant water in the spiral cupper tube, was used for kept constant to the electrolyte temperature. 
Mitutoyo SJ-400 profilometer used for the surface roughness measurement. Fisher-Dualscope MP40E-S was performed for coating thickness measurement. Brukers D8 (40kW, 40mA) type X-ray diffract meter was used for identification of the phases. X-ray diffraction (XRD) was conducted with $\mathrm{Cu} \mathrm{K \alpha}$ radiation. Between $20^{\circ}$ to $90^{\circ}$ degrees were scanned with a step increment of $0.02^{\circ}$ and account time of 1s. Cross-sectional analyses were investigated by Philips XL30 type field emission Scanning Electron Microscopy (SEM). Mitutoyo MicroWizhard micro-hardness tester was used for cross-sectional hardness tests with under indentation load of $20 \mathrm{gr}$. The elemental analysis of the aluminium substrates was investigated with SpectroMax LMF14 spectroscopy measurement machine and the results are given in Table 1.

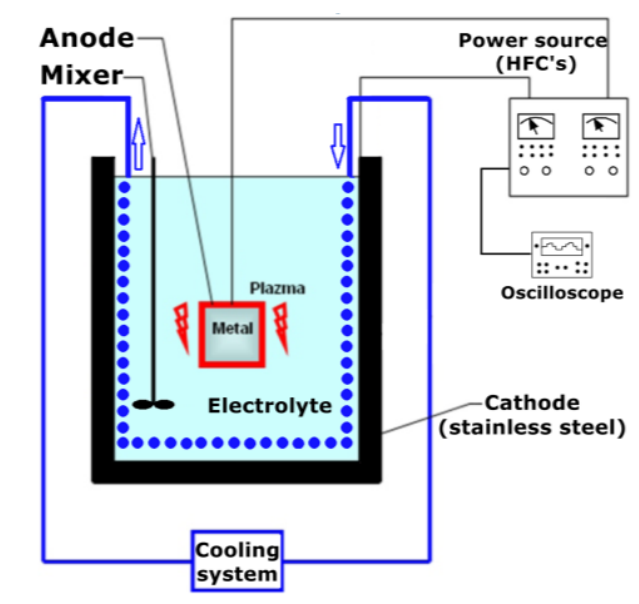

Fig. 1: The schematic diagram of the MAO device.

Table 1: Spectral analysis of substrate.

\begin{tabular}{|c|c|c|c|c|c|c|c|c|c|c|}
\hline $\mathrm{Al}$ & $\mathrm{Si}$ & $\mathrm{Mg}$ & $\mathrm{Cu}$ & $\mathrm{Mn}$ & $\mathrm{Fe}$ & $\mathrm{Zn}$ & $\mathrm{Sn}$ & $\mathrm{Pb}$ & $\mathrm{V}$ & $\mathrm{Cr}+\mathrm{B}+\mathrm{Cd}+\mathrm{Na}+\mathrm{Ti}+\mathrm{Ca}+\mathrm{Bi}$ \\
\hline 98,6 & 0,47 & 0,46 & 0,03 & 0,017 & 0,25 & 0,011 & 0,06 & 0,042 & 0,011 & 0,0214 \\
\hline
\end{tabular}

The samples prepared which has $4 \mathrm{~cm}^{2}$ surface areas. All substrates were mechanically ground with 200-1200 mesh emery papers and cleaned ultrasonically for $5 \mathrm{~min}$ with acetone.

There are several electrical process parameters could be investigated but in this study the pulse durations effects searched, thus some other parameters were kept constant and they were given in Table 2.

Table 2: Constant parameters and their values.

\begin{tabular}{|l|l|}
\hline \multicolumn{1}{|c|}{ Parameter } & \multicolumn{1}{c|}{ Values } \\
\hline Anode voltage $(\mathrm{Va})$ & $500 \mathrm{~V}$ \\
\hline Cathode voltage $(\mathrm{Vk})$ & $400 \mathrm{~V}$ \\
\hline Duty cycle & $8 \%$ \\
\hline Coating time & 20 minutes \\
\hline Electrolyte temperature & $25^{\circ} \mathrm{C} \pm 5$ \\
\hline Electrolyte composition & $\mathrm{KOH}(2 \mathrm{~g} / \mathrm{l}), \mathrm{Na} 2 \mathrm{SiO} 3.5 \mathrm{H} 2 \mathrm{O}(9,5 \mathrm{~g} / \mathrm{l})$ \\
\hline
\end{tabular}

Pulse duration couples and the sample codes were given in Table 3.

Table 3: Pulse duration's couple's values.

\begin{tabular}{|l|c|c|c|c|c|}
\hline Cathode pulse duration, $\mu \mathrm{s}$ & 200 & 600 & 800 & 1000 & 2500 \\
\hline Anode pulse duration, $\mu \mathrm{s}$ & 300 & 800 & 1000 & 1800 & 3800 \\
\hline Pulse duration couple code & $\mathrm{C} 1$ & $\mathrm{C} 2$ & $\mathrm{C} 3$ & $\mathrm{C} 4$ & $\mathrm{C} 5$ \\
\hline
\end{tabular}




\section{Results and Discussion}

Coatings thickness was given in Fig. 2. With the increasing of pulse duration couple's there were occurred 3 different regime of coating thickness. With short duration thickness is around $80 \mu \mathrm{m}(\mathrm{C} 1)$, increasing of the duration created a thicker coating layer as between $85-90 \mu \mathrm{m}(\mathrm{C} 2, \mathrm{C} 3)$, with the highest pulse durations' the coatings are getting lower $(\mathrm{C} 4, \mathrm{C} 5)$.

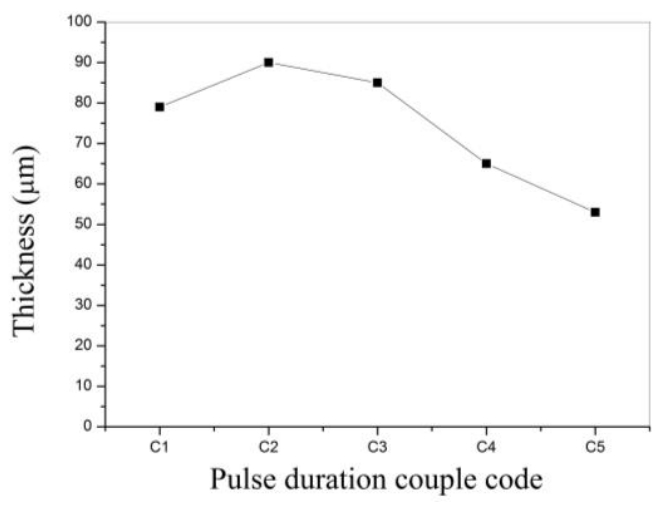

Fig. 2: Influence of pulse durations couple on the coating thickness.

The surface roughness of MAO coatings results under different pulse duration couple modes is shown in Fig. 3. It was obvious that the surface roughness' results are in the same direction with coating thickness. There occurred 3 regimes with different pulse durations. It should also be noted that $[6,9-11]$ surface roughness was closely related with the coating thickness.

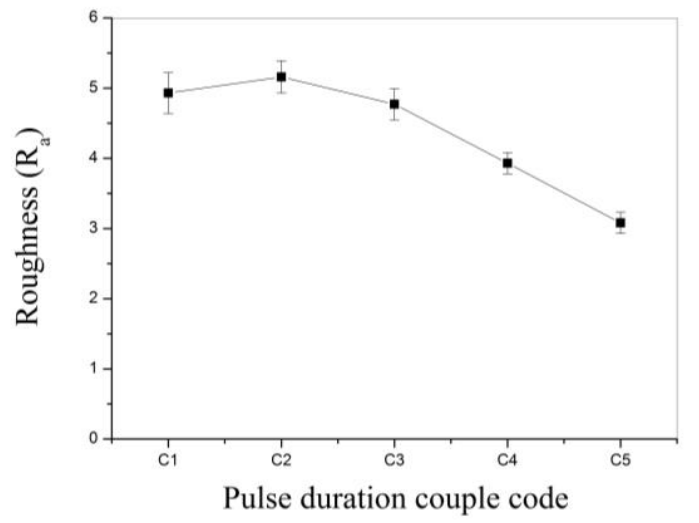

Fig. 3: Influence of pulse durations couple on the surface roughness.

The effect of pulse duration on the phase composition of MAO coatings was obtained by XRD analysis as given in Fig. 4. The diffraction peaks of $\mathrm{Al}$ and $\mathrm{Mg}_{2} \mathrm{Si}$ were excited from the $\mathrm{Al}$ alloy substrate, which stated that the content of $\mathrm{Al}$ is most. The reason for this may be the structure of the coatings, which has a lot of pores through to the substrate and X-rays can detect the substrate. Thus, the increasing of coating thickness decreased the strength of the $\mathrm{Al}$ and $\mathrm{Mg}_{2} \mathrm{Si}$ peaks. The characteristic peaks corresponding to $\gamma-\mathrm{Al}_{2} \mathrm{O}_{3}$ and $\alpha-\mathrm{Al}_{2} \mathrm{O}_{3}$. Therefore, it can be concluded that the aluminium oxides in the MAO coatings was mainly crystalline. It is clearly deduced that all MAO coated specimens have the $\gamma-\mathrm{Al}_{2} \mathrm{O}_{3}$ peaks and with the increasing of the coating thickness the intensity of $\alpha-\mathrm{Al}_{2} \mathrm{O}_{3}$ increased. Thus, the results of the XRD analysis farther verified that the MAO coatings had a more intensify structure with the changing of pulse duration couple. 


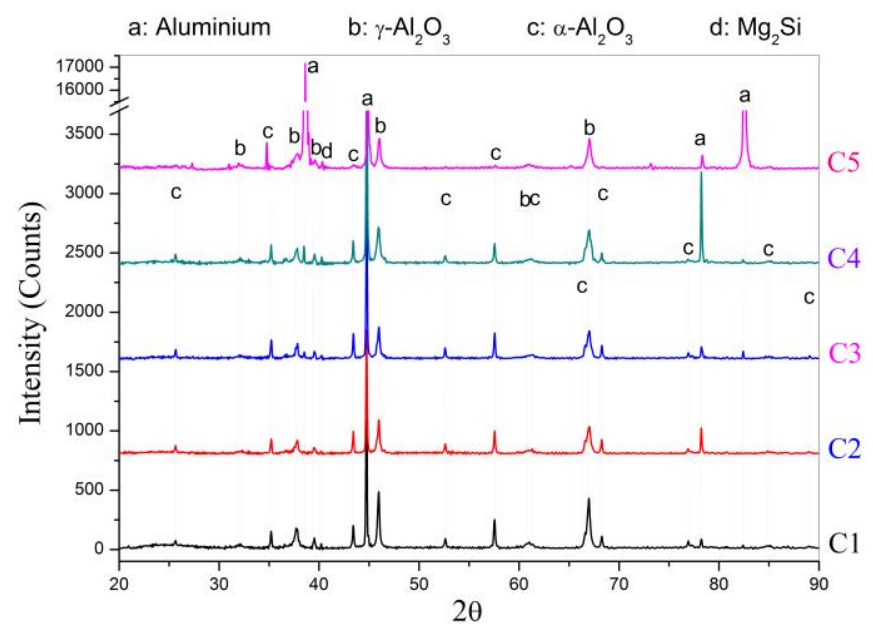

Fig. 4: XRD results of the coatings prepared at different pulse durations couple.

The hardness profiles of coatings were given in Fig. 5. Due to the nature of the process the outer layer has a porous structure, which is mostly consisted of $\gamma-\mathrm{Al}_{2} \mathrm{O}_{3}$ phase, while the inner layer is a tighten structure and it is mostly consisted of $\alpha-\mathrm{Al}_{2} \mathrm{O}_{3}$ phase $[10,12]$. This lamination may affect the hardness profile results by the distance from surface. The inner layer, which has aluminium oxide phases, hardness' measured between 1200-2000 Vicker's at the depth of approximately $25 \mu \mathrm{m}$ from the coating surface. The hardness decreased $(\mathrm{C} 4, \mathrm{C} 5)$ dramatically at the depth of $70 \mu \mathrm{m}$ from the coating surface where feeling the presence of substrate began. Because of hard $\alpha-\mathrm{Al}_{2} \mathrm{O}_{3}$ phase was present very near to the substrate-coating interface, the hardest points are between 30-60 $\mu \mathrm{m}$ from the coating surface [13]. On the other hand the porosity of the coating reduced the hardness [10].

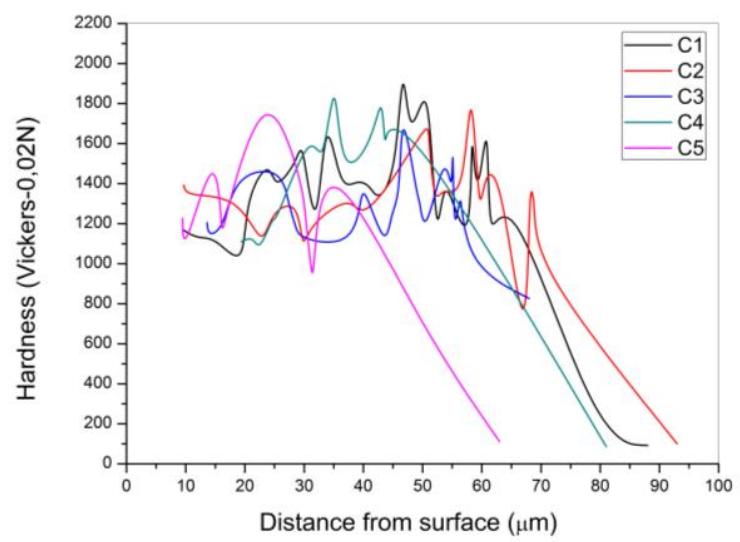

Fig. 5: Vickers hardness profiles of the coatings fabricated under different anode-cathode pulse duration couples.

Cross sectional SEM image of sample C2 was given in Fig. 6. Sparks discharge holes may reach to the substrate from the surface of the coating as shown in Fig. 6. This holes carry the melted metal though to surface and solidified on it. This rapid solidification of the molten alumina occurred microcraks and porous surface [14]. By the increasing of the thickness, transformation from $\gamma-\mathrm{Al}_{2} \mathrm{O}_{3}$ phase to $\alpha-\mathrm{Al}_{2} \mathrm{O}_{3}$ phase has begun in the inner layer. It has reported that $\gamma-\mathrm{Al}_{2} \mathrm{O}_{3}$ phase occurred due to the high cooling rate, while more $\alpha-\mathrm{Al} 2 \mathrm{O} 3$ phase can be explored in the inner layers due to the low cooling rate [9]. With cross sectional micrographs, Fig. 6, we found the inner layer demonstrated as an orange peel appearance. 


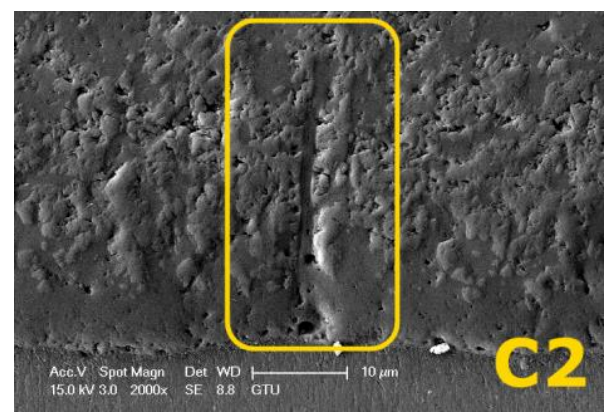

Fig. 6: An SEM micrograph of the sample C2 (discharge hole).

Cross sectional SEM images of C1, C2, C3, C4 and C5 were given in Fig. 7. The outer layers of C2-C3 have more micro pores compare with $\mathrm{C} 1$, due to the long pulse durations. On the other hand long pulse duration generated much $\operatorname{more} \alpha-\mathrm{Al}_{2} \mathrm{O}_{3}$ phase and thicker coating in contrast with $\mathrm{C} 1$. Increasing the anodic-cathodic pulse durations, like as C4-C5, has clearly damaged the coating layers. The thicknesses are getting low and there is almost no orange peel appearance on C5 crosssectional morphology in Fig. 7.
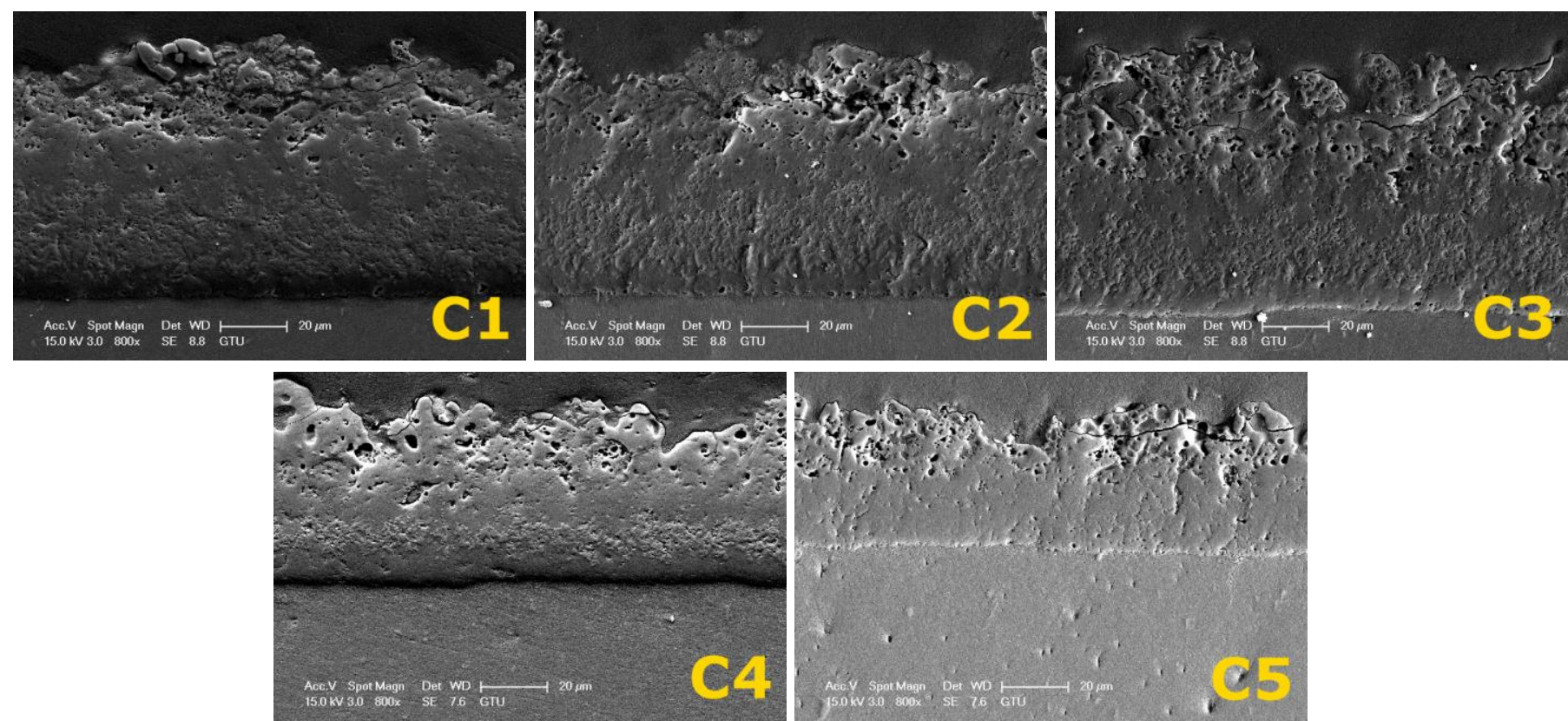

Fig. 7: A cross-sectional morphology of the ceramic coatings.

\section{Conclusion}

In this paper the effect of pulse duration couple on properties of coating was investigated with five different pulse duration parameters.

It was found that short pulse durations are achieving high quality inner dense layer. Increasing of pulse durations lead to a significant increase in thickness but occurred more porous layer.

Hardness and XRD phase analysis proved that $\alpha-\mathrm{Al}_{2} \mathrm{O}_{3}$ was obtained for whole range of pulse durations. Increase in hardness apparently is due to the combine affect of increase in volume percent of $\alpha-\mathrm{Al}_{2} \mathrm{O}_{3}$ and decrease in volume percent of pore.

A coating layer of $90 \mu \mathrm{m}$ was achieved by 20 minutes of processing time that is rate of growth is $4.5 \mu \mathrm{m} / \mathrm{min}$ with experiment C3. Succeeding of this growth rate is an evidence of that the present process is energy efficient and don't need more pulse duration. Further increase in quality of coating need to investigated on other electrical parameters. 


\section{Acknowledgements}

The authors express their thanks to technicians Adem Sen and Ahmet Nazim for their kind assistance during XRD and SEM experimental studies. The work was carried out with financial support from the Scientific and Technological Research Council of Turkey (TUBITAK) / Project Name: 2211-C Scholarship of National Priority Subjects Doctoral Thesis Programme.

\section{References}

[1] Z. J. Wang, L. N. Wu, Y. L. Qi, W. Cai, Z. H. Jiang, "Self-lubricating $\mathrm{Al}_{2} \mathrm{O}_{3} / \mathrm{PTFE}$ composite coating formation on surface of aluminium alloy," Surf Coat Tech, vol. 204, pp. 3315-3318, 2010.

[2] C. Taschner, B. Ljungberg, V. Alfredsson, I. Endler, A. Leonhardt, "Deposition of hard crystalline $\mathrm{Al}_{2} \mathrm{O}_{3}$ coatings by bipolar pulsed dc PACVD," Surf Coat Tech, vol. 108, pp. 257-264, 1998.

[3] F. Fietzke, K. Goedicke, W. Hempel, "The deposition of hard crystalline $\mathrm{Al}_{2} \mathrm{O}_{3}$ layers by means of bipolar pulsed magnetron sputtering," Surf Coat Tech, vol. 86-7, 657-663, 1996.

[4] R. Emmerich, B. Enders, H. Martin, F. Stippich, G. K. Wolf, P. E. Andersen, J. Kudelha, P. Lukac, H. Hasuyama, Y. Shima, "Corrosion protection ability of Al2O3 coatings deposited with ion beam assisted deposition," Surf Coat Tech, vol. 89, pp. 47-51, 1997.

[5] B. H. Kear, Z. Kalman, R. K. Sadangi, G. Skandan, J. Colaizzi, W. E. Mayo, "Plasma-sprayed nanostructured Al2O3/TiO2 powders and coatings," J Therm Spray Techn, vol. 9, pp. 483-487, 2000.

[6] A. L. Yerokhin, X. Nie, A. Leyland, A. Matthews, S. J. Dowey, "Plasma electrolysis for surface engineering," Surf Coat Tech, vol. 122, pp. 73-93, 1999.

[7] L. O. Snizhko, A. L. Yerokhin, N. L. Gurevina, V. A. Patalakha, A. Matthews, "Excessive oxygen evolution during plasma electrolytic oxidation of aluminium," Thin Solid Films, vol. 516, pp. 460-464, 2007.

[8] A. L. Yerokhin, A. Shatrov, V. Samsonov, P. Shashkov, A. Pilkington, A. Leyland, A. Matthews, "Oxide ceramic coatings on aluminium alloys produced by a pulsed bipolar plasma electrolytic oxidation process," Surf Coat Tech, vol. 199, pp. 150-157, 2005.

[9] T. B. Wei, F. Y. Yan, J. Tian, "Characterization and wear- and corrosion-resistance of microarc oxidation ceramic coatings on aluminum alloy," J Alloy Compd, vol. 389, pp. 169-176, 2005.

[10] M. S. Yilmaz, O. Sahin, "Applying High Voltage Cathodic Pulse with Various Pulse Durations on Aluminium via Micro-Arc Oxidation (MAO)," Surf Coat Tech, vol. 347, pp. 278-285, 2018.

[11] M. S. Yilmaz, O. Sahin, "Effects of Pulse Duration on Structure and Surface Characteristics of Micro-Arc Oxidation Coatings Formed on Aluminum Alloy," Acta Physica Polonica A, vol. 129, pp. 673-676, 2016.

[12] Y. J. Guan, Y. Xia, G. Li, "Growth mechanism and corrosion behavior of ceramic coatings on aluminum produced by autocontrol AC pulse PEO," Surf Coat Tech, vol. 202, pp. 4602-4612, 2008.

[13] W. B. Xue, X. L. Wu, X. J. Li, H. Tian, "Anti-corrosion film on 2024/SiC aluminum matrix composite fabricated by microarc oxidation in silicate electrolyte," J Alloy Compd, vol. 425, pp. 302-306, 2006.

[14] K. Wang, B. H. Koo, C. G. Lee, Y. J. Kim, S. H. Lee, E. Byon, "Effects of electrolytes variation on formation of oxide layers of $6061 \mathrm{Al}$ alloys by plasma electrolytic oxidation," T Nonferr Metal Soc, vol. 19, pp. 866-870, 2009. 